\title{
El debate entre los antiguos y los modernos. A propósito de las interpretaciones del escepticismo de Michel de Montaigne
}

\author{
The Debate Between The Ancients And \\ The Moderns. On Michel De Montaigne's \\ Skepticism Interpretations
}

\author{
Vicente Raga RosalenY \\ C.U.E. Alexander von Humboldt, Armenia-Quindío, Colombia
}

Recibido: 14/09/2009

Aceptado: 21/01/2010

\section{Resumen}

Actualmente existe un debate en torno a la "naturaleza" del escepticismo del escritor renacentista francés Michel de Montaigne que puede remedar, en cierto modo, la querella entre los antiguos y los modernos. Algunos autores creen que Montaigne es un completo innovador, que rompió totalmente con la tradición escéptica antigua. Otros, sin embargo, piensan que apenas ha aportado novedades a los argumentos escépticos y que su papel se reduce al de mero transmisor del pensamiento antiguo olvidado en la Modernidad.

Frente a ambas interpretaciones, nuestra intención será, primero, exponer la relevancia del escepticismo montaniano en sus Essais. En segundo lugar, daremos cuenta de las dos posiciones heurísticas mencionadas, renovadora y tradicional, evidenciando sus límites. Con ello trataremos de concluir el carácter "verdaderamente" escéptico de la skepsis montaniana, innovadora y tradicional a la vez, que se resiste a los intentos de clasificación dogmática de las teorías, tradicionales o renovadoras, que tratan de imponerle sus propios sistemas y no de leer al autor en sus términos.

Palabras clave: escepticismo, hermenéutica, antigüedad, modernidad. 


\begin{abstract}
Now, there is a debate about the "nature" of the Renaissance French writer Michel de Montaigne's skepticism that could be similar, in some way, to the Quarrel between the Ancient and the Modern. Some authors believe that Montaigne was a completely innovative author, who would have broken completely with the ancient skeptical tradition. Others, however, feel that he has made little changes in the skeptical arguments and that his role would be reduced to a mere transmitter of the ancient forgotten thought.

Faced with both interpretations, it would be our intention, first of all, to explain the relevance of the montanian skepticism, its importance in the work of the author, and second exposing traditional and innovative positions, make clear their limits. This try to conclude the "truly" skeptical nature the of montanian skepticism, innovative and traditional at the same time. In addition, it attempts to resist the classification of dogmatic theories, traditional or renewal, which would seek to impose their own systems rather than read the author in his own terms.
\end{abstract}

Keywords: Skepticism, Hermeneutics, Antiquity, Modernity.

Montaigne ha pasado a la historia del pensamiento, en los tradicionales manuales de historia de la filosofía, por ser un autor secundario, escasamente original y poco relevante en sus aportaciones filosóficas, mucho más interesante por sus aportaciones estilísticas, como inventor del género ensayístico, como humanista culto y renovador de las letras francesas, en definitiva, como escritor más que como pensador. ${ }^{1}$

Tal situación tan poco ventajosa para el autor renacentista, al menos en el campo filosófico, ha variado con la fortuna de la interpretación, debida a Richard $\mathrm{H}$. Popkin, de la importancia del "redescubrimiento" del escepticismo en el Renacimiento para el desarrollo del pensamiento moderno. Desde esta lectura, Montaigne se perfila como un autor central en la transmisión del pensamiento antiguo a nuestro tiempo y, al mismo tiempo, como un paradigma del encuentro y fusión en un momento de crisis de dos Weltanschauung, la pagana y la cristiana, dotando de una particularidad especifica al "renacimiento" del pensamiento aporético en nuestra época.

\footnotetext{
1 Por ejemplo, Hegel apenas habla una sola vez de Montaigne en el conjunto de su obra, dedicándole además una línea y contribuyendo así a perpetuar la tópica imagen de un Montaigne ajeno al campo filosófico y cuyo estudio sería más competencia de aquellos interesados por la literatura (Hegel, G. W. F.: Lecciones sobre la historia de la filosofia, vol. III, FCE, México, 1955, p. 191).
} 
Así las cosas, el nuevo retrato del autor renacentista francés se dibujaría con colores más amables pero, aún persistirían una serie de tensiones y ambigüedades que restarían brillo al conjunto y desafiarían los intentos de leer a Montaigne de una manera integra y homogénea, de introducirlo en el panorama académico filosófico de manera decidida.

Ciertamente, en la interpretación más difundida, desde Popkin, el perfil de Montaigne no ofrece excesivos problemas: pensador escéptico pirrónico y, a la vez, católico confeso y practicante de una vertiente dentro del catolicismo, la fideísta, el título de pirronista cristiano, o el de fideísta escéptico, sería el que mejor encajaría en su descripción. Pero, ¡ icuantos interrogantes ha suscitado este marbete! Y es que, si ciertamente es un tópico calificar a Montaigne de escéptico, ha sido motivo de amplios desacuerdos la adscripción del mismo a la corriente pirrónica. Pero, aún más interesante, tal consideración escéptica de Montaigne, ¿puede deslindarle de la lectura de su obra como texto menor, destinada tan sólo a la mera difusión de un pensamiento ajeno, el escéptico, que el francés meramente habría dado a conocer al gran público?

Así pues, la cuestión que queremos plantear en nuestro artículo es la siguiente: ¿ha sido el escepticismo de Michel de Montaigne una mera reproducción de las enseñanzas de las antiguas corrientes escépticas? $\mathrm{O}$, ¿debemos hablar de una ruptura moderna en el trabajo montaniano, con una visión radicalmente distinta del dudar escéptico clásico? Hay defensores de ambos partidos en este debate de los antiguos y los modernos, pero nadie hasta ahora ha planteado una visión de conjunto que responda a la disputa que más claramente separa a los intérpretes contemporáneos del escritor francés y nosotros trataremos, por ello, de dar respuesta a esta vexata quaestio en nuestro artículo.

\section{1. ¿Montaigne escéptico?}

Muchas son las cuestiones que suscita la interpretación de los Essais montanianos, más allá de su comprensión como obra maestra de las letras francesas o como expresión de un precedente del escepticismo "verdaderamente" filosófico de su compatriota René Descartes. Por ello, tratando de iluminar tal debate frente a las lecturas tradicionales o acomodaticias, nuestro trabajo no se reducirá, como tantos otros a una lectura del texto habitualmente considerado como el culmen del escepticismo montaniano, la Apología de Raimundo Sabunde 2 , antes bien, y alineándonos con aquellas interpretaciones que hacen del escepticismo una constante del pen-

\footnotetext{
2 Utilizamos aquí la versión castellana del nombre de este teólogo que hemos visto más difundida en los textos vertidos a esta lengua en los que resulta mencionado.
} 
samiento del autor francés, recurriremos a textos pertenecientes a los diferentes volúmenes y estados redaccionales o ediciones de los Essais $^{3}$.

Pero, contra nuestra opción de lectura, así como en oposición a lo que viene siendo un tópico de los más ampliamente admitidos, no es homogénea la opinión respecto a la calidad escéptica del pensamiento montaniano, bien como mero transmisor de estas corrientes del pensamiento, bien como participante activo en su elaboración y renovación. Oponiéndose incluso a las propias declaraciones del pensador:

C'est par mon experience que j'accuse l'humaine ignorance, qui est, à mon advis, le plus seur party de l'escole du monde. ${ }^{4}$

algunos autores dudan de la sinceridad de la posición escéptica del autor francés en sus Essais y siendo éste el punto de partida de nuestro análisis no podemos dejar de atender en primer lugar a las discusiones que al respecto de este punto se han generado, tratando de dilucidar si, finalmente, el propio inicio de nuestro trabajo tiene algún sentido o no.

Sin duda es Pierre Villey un autor relevante en la historia de la interpretación académica de los Essais $^{5}$ y su punto de vista tiene un peso central en cualquier nuevo intento de aproximación a la obra del autor francés. Y si este exegeta ya deja entrever su desacuerdo con nuestra opción interpretativa en el establecimiento de su tesis central, en relación con las etapas en el pensamiento del autor francés, a saber, la etapa estoica, seguida de la crisis escéptica que desembocaría, finalmente, en la de un pensamiento epicúreo sui generis, no lo hace menos al plantear, de manera más matizada e interesante, el carácter ecléctico del pensamiento montaniano. ${ }^{6}$

Así, siguiendo tal interpretación, sería propio del autor francés no seguir servilmente a ninguna de las escuelas del pensamiento antiguo $\mathrm{y}$, de este modo, escogiendo sus propios principios de acción, habría tomado de entre las opiniones en debate y contradicción de los antiguos aquellas que le resultaran mejor planteadas, adop-

\footnotetext{
3 Citaremos los Essais de Michel de Montaigne utilizando siempre el mismo sistema: en el cuerpo del texto la cita en francés del autor según queda recogida en sus Oeuvres complètes en la edición de Thibaudet y Rat (Montaigne, M. de: Oeuvres complètes, Gallimard, París, 1962), seguidamente en nota indicaremos el libro de los Essais en números romanos, en arábigos el del ensayo en concreto y la página de las Oeuvres donde localizar la referencia realizada, así como la traducción al castellano de Picazo y Montojo en Cátedra (modificada en diversos momentos por mor de una mayor fidelidad al texto francés, Montaigne, M. de: Ensayos, 3 vols., Cátedra, Madrid, 1998).

4 III, 13, 1053: "Declaro por propia experiencia la ignorancia humana, lo cual es, a mi parecer, el partido más seguro de la escuela del mundo".

${ }^{5} \mathrm{Si}$ sus tesis heurísticas centrales respecto de las etapas del pensamiento montaniano han sido ampliamente cuestionadas por los estudiosos que le han sucedido, sigue siendo su obra pionera en el estudio exhaustivo de las fuentes de la obra de Michel de Montaigne, Les sources et l'evolution des Essais de Michel de Montaigne, un texto ineludible y, en muchos aspectos, insuperado.

6 Villey, P.: Les sources et l'evolution des Essais de Montaigne, Hachette, París, 1908, p. 30.
} 
tando una moral del libre examen o la autonomía, respetuosa eso sí, de las costumbres morales, religiosas y políticas, con la que llegar a una posición muy personal que, para nada, le comprometería con una doctrina u otra. Esta tesis, prudente y matizada, se acompañaría, sin embargo, de otras más decididas y radicalmente problemáticas, para nuestro artículo, como, especialmente, aquella que asevera, complementariamente con la tesis evolutiva y la ecléctica, que Montaigne no sería un "verdadero" escéptico. ${ }^{7}$

Y es que, para Villey, Montaigne no se encontraba "flotando incesantemente en una incertidumbre infinita" sin alcanzar en algún momento un punto sólido en el que fijar su propia posición, ni era un pirrónico convencido, sino que ésta es una posición adoptada en un momento de crisis y empleada contra los dogmatismos y las novedades de la época, que tantas guerras y desgracias habían provocado, siendo abandonada por Montaigne poco tiempo después. Y la razón principal para realizar tales aseveraciones radicaría en el convencimiento, por parte del exegeta francés, de que el escepticismo, entendido de manera radical, como suspensión de juicio y vida adoxastica no es una posición vivible.

Esta objeción, claramente formulada después por otros autores en relación con Montaigne, pudiendo considerarlo, aún así, un escéptico consecuente (aunque insincero $)^{8}$, o inconsecuente e incompleto ${ }^{9}$, se vincula a una de las objeciones clásicas al escepticismo pirrónico, al menos al modo como lo expone Sexto Empírico, quien en sus obras tomó nota de ella. Nos referimos a la apraxia, la supuesta imposibilidad, e incluso inmoralidad, en que debe verse envuelta la propuesta de una vida escéptica consecuente, al decir de muchos críticos de la Antigüedad, y que habría vuelto con fuerza en tiempos modernos ${ }^{10}$.

\footnotetext{
7 Villey, P.: op. cit., p. 155.

8 Como Lévi-Strauss, Cl.: "Releyendo a Montaigne", en Cl. Levi-Strauss: Historia de Lince, Anagrama, Barcelona 1992, p. 275, que entiende el escepticismo montaniano como integral al tiempo que categóricamente invivible y que, por eso mismo, aboga por una insinceridad intelectual del pensador francés que permitiera dotar de sentido a la vida.

9 Como Limbrick, E.: "La relation du scepticisme avec la subjectivité", en E. Kushner (ed.): La problématique du sujet chez Montaigne, Champion, París 1995, p. 82, que defiende la necesidad de una vida basada, al menos, en la probabilidad, abogando por un conocimiento montaniano del yo, en contraste con un escepticismo sui generis sobre el conocimiento del mundo externo.

10 A través de la historia, el escepticismo ha sido acusado de inconsistente, irracional, absurdo, inmoral y políticamente complaciente incluso con los regimenes más denostados. Muchas veces tales cuestionamientos han tomado la forma del argumento clásico de la autorrefutación (si el escepticismo implica una suspensión de juicio general, ¿por qué no aplicarla a la propia actividad de la epoché ?) y, en definitiva, la conclusión de tales ataques ha sido la de negar la posibilidad de vivir el escepticismo. Más recientemente autores como Frede y, sobre todo, Burnyeat han reavivado este cuestionamiento clásico mediante un animado debate (véase Burnyeat, M. F.: "Can the Skeptic Live his Skepticism?", en M. F. Burnyeat (ed.): The Skeptical Tradition, University of California Press, Berkeley, 1983, pp.
} 
Y eso mismo puede decirse de una variante diversa, pero igualmente encaminada a señalar la inviabilidad del escepticismo, que hace hincapié en el carácter autocontradictorio y, en esa medida, autorrefutatorio, del gesto escéptico. Y es que el escepticismo de Montaigne, en esta versión de la objeción a su adscripción completa al pirronismo, si bien puede ligarse a una sui generis posición crítica con el racionalismo extremado, no podría hacerlo con la supuestamente autocontradictoria renuncia a cualquier tipo de creencia y posición firme. ${ }^{11}$

Desde esta perspectiva, Montaigne no es un escéptico de escuela12, siendo la suya, más bien, una reacción a los males del dogmatismo, a las precariedades de su época y a la crisis de su mundo cultural. Un escepticismo el suyo, pues, funcional, enfocado a interpretar las carencias y puntos críticos de su momento histórico, así como de cierto fondo permanente de la condición humana, que surge de un análisis detallado de la interioridad del ser humano y de la memoria colectiva de la humanidad, que invita antes a la prudencia o cautela intelectual y a la tolerancia, que al supuesto indiferentismo pirrónico. 13

Puede entenderse desde esta perspectiva diluida, el escepticismo montaniano como una adquisición definitiva de su espíritu, antes que como una mera "crisis"14. Y así, su adscripción a las corrientes escépticas, es en este caso tan moderada que pasa, al menos en los autores citados, por una admisión de algún tipo de limite del dudar y una afirmación de conocimiento poco consistente con las posiciones escépticas al modo en que las expuso la fuente documental principal del pensador francés, Sexto Empírico. Así las cosas, dentro de estas corrientes interpretativas dominantes se han señalado tales límites en el ámbito de la moral y en el conocimiento del propio yo, tema central de Michel de Montaigne en los Essais.

De este modo, de acuerdo con la primera de las supuestas limitaciones del autor francés, si bien puede admitirse un cierto escepticismo instrumental en el ámbito teórico, en el campo moral Montaigne tomará opciones cognoscitivas claras, aunque sin aspirar a universales morales, basándose, según lecturas, en una escuela moral, como la epicúrea15, o en algún aspecto difuso de la filosofía práctica que

117ss y Frede, M.: “The Sceptic's Beliefs", en M. F. Burnyeat y M. Frede (eds.): The Original Sceptics: a Controversy, Hackett, Cambridge, Indianapolis 1997, pp. 127ss) en torno a la vertiente epistemológica del problema y, asimismo, autoras como Martha Nussbaum o Julia Annas han contribuido a la cuestión desde el lado ético y político.

11 Chamizo, P. J.: La doctrina de la verdad en Michel de Montaigne, Publicaciones de la Universidad de Málaga, Málaga, 1984, p. 172.

12 De la "Introducción" de Pere Lluís Font a la Apología de Montaigne (Font, P. Ll.: "Introducció", en M. de Montaigne: Apología de Ramon Sibiuda, trad. de Jaume Casals, Laia, Barcelona, 1982, p. 26).

13 Casals Pons, J.: La filosofia de Montaigne, Edicions 62, Barcelona, 1986, p. 64.

14 Comte-Sponville, A.: "Montaigne cynique? (Valeur et vérité dans les Essais)", en Revue Internationale de Philosophie, 181: 2 (1992), p. 236.

15 Comte-Sponville, A.: op. cit., p. 258. 
tenga como su principio un descubrir la naturaleza y seguirla en su multiplicidad ${ }^{16}$.

En definitiva, pues, el escepticismo choca aquí con el sentimiento moral, manteniendo éste su supremacía ${ }^{17}$, como un elemento necesario para dotar de coherencia a la posición montaniana. Y esto engarza con el carácter "invivible" del escepticismo ya que tales creencias morales no sólo actúan como un garante para salvar la autorefutación de una epoché demasiado rigurosa, sino que, además, "todo escéptico tiene creencias que parecerían resistir la duda"18, en concreto para Montaigne aquellas relacionadas con la intención moral que determina cómo vivir, así como algunos rasgos característicos del filosofar, tales como, por ejemplo, la defensa de los habitantes del Nuevo Mundo.

Y así, siguiendo esta última tesis, si a Montaigne se le ha concebido eminentemente como un moralista, como un defensor de la tolerancia en tiempos de persecución dogmática, con guerras de religión en el Viejo Mundo, y exterminios masivos en el Nuevo, tales mimbres éticos deben apoyarse en algún tipo de posición moral, en unas creencias, ya que la tolerancia no podría fundarse tan sólo en el escepticismo ${ }^{19}$. Desde esta lectura la skepsis conlleva un estado de indiferencia, así como una imposibilidad a la hora de arbitrar en conflictos entre doctrinas comprehensivas, que desaconseja, desde el lado moral y desde el epistemológico, su práctica coherente.

El escepticismo montaniano será imposible de entender como completo, no puede seguirse hasta sus últimas consecuencias porque la vida conlleva un mínimo de decisiones morales y compromisos y, por ello mismo, cabe buscar en Montaigne un giro hacia la moralidad, sin necesidad de vincular su adhesión a la corriente escéptica a un momento temporal de crisis, pero si matizando su relación con éste. Tal giro, como han argumentado otros exegetas de la obra montaniana, se relaciona, precisamente, con el segundo de los límites planteados al escepticismo, el de la búsqueda de la interioridad, la investigación del yo montaniano en los Essais.

De esta manera, si ya desde los primeros ensayos el único privilegio y autoridad que Montaigne paree reconocer al espíritu humano es el de criticarse a sí mismo, el de reconocer su debilidad, quedando la verdad más allá de nuestro alcance, en la esfera indecidible de lo divino, ¿por qué no entender tal posición, ligada al supuestamente ineludible compromiso ético y al camino de introspección abierto por los Essais, como una defensa de una forma de conocimiento segura, la del propio yo, contrapuesta a la del mundo externo, sumida en el escepticismo?20

\footnotetext{
16 Casals Pons, J.: "trois incursions de Montaigne dans la métaphisique", en Cl. Blum (ed.): Montaigne penseur et philosophe (1588-1988), Champion, París, 1990, p. 200.

17 Emerson, R. W.: "Montaigne o el escéptico", en Th. Carlyle y R. W. Emerson: De los héroes. Hombres representativos, Océano, Barcelona, 1999, p. 331.

18 Lom, P.: The Limits of Doubt, State University of New York Press, New York, 2001, p. 75.

19 Lom, P.: op. cit., p. 88.

20 Ésta es la idea que, de manera expeditiva, defiende Defaux, G.: "Montaigne chez les sceptiques: essai de mise au point", en French Forum, 23: 2 (1998), pp. 147ss.
} 
Desde esta lectura, si ni los sentidos, ni el entendimiento humano, proporcionan certidumbre objetiva, dado el escepticismo epistemológico esgrimido por el autor de los Essais, será la subjetividad del juicio, el "yo", el que se asentará con certeza anunciando, de este modo, aquello que en Descartes continúa y culmina ${ }^{21}$. Este conocimiento intimo, referido incluso desde una seguridad dogmática por Montaigne $^{22}$, da cuenta de nuevo, de los límites que la coherencia, y la moralidad imponen al escepticismo.

Y así puede decirse que a todas estas exégesis opuestas a la posibilidad de una presencia plena y vivible, del escepticismo en los Essais, les subyace una perspectiva instrumental del discurrir escéptico. Esto es, que las objeciones tradicionales al escepticismo, en el concreto caso montaniano, tienen como telón de fondo una comprensión del dudar escéptico como medio útil para otros logros, bien porque tras un período crítico dejase de tener vigencia la corriente pirrónica primeramente aceptada, bien porque ésta quedase siempre en un segundo plano crítico, con metas éticas.

Sin embargo, centrándonos en el aspecto moral, eje de algunas de las objeciones mostradas, ¿por qué ha de ser necesariamente inconsistente la posición escéptica atribuible al autor francés con una búsqueda propia de la filosofía práctica? ¿Tiene que ser invivible o inmoral una postura escéptica rigurosa o estar limitada, en pro de una cierta coherencia lógica, por el ámbito moral o el del conocimiento del propio yo?

Podemos empezar diciendo que en la medida en que existe una ética propiamente pirrónica, con las diversas variantes que se manifiestan de Pirrón a Sexto, y de éstos a los académicos de la Academia Media y Nueva, es posible poner en cuestión muchas de las aseveraciones planteadas por los críticos a la posibilidad del escepticismo montaniano en los Essais.23

Así pues, frente a lo que otros investigadores aseveran, cabe ver si uno de los posibles modelos de una filosofía práctica como la montaniana, basada en la facultad de juicio y en un especial "conocimiento" de sí, no tendrá su origen en aquello que sobre la ética puede encontrarse en la exposición del pensamiento académico en Cicerón ${ }^{24}$, así como en las reglas seminales de la vida escéptica según Sexto y en la comprensión pirrónica de la identidad entre filosofía y praxis.

De este modo, si uno atiende, por ejemplo, a reconstrucciones como la que Morrison realizara de la comprensión de la vida práctica por Carneades ${ }^{25}$, puede ver

${ }^{21}$ Limbrick, E.: "Le scepticisme provisoire de Montaigne”, en F. Moureau, R. Granderoute y Cl. Blum (eds.): Montaigne et les Essais-1580-1980, Champion-Slatkine, París-Ginebra, 1983, pp. 176.

22 Defaux, G.: op. cit., p. 157.

23 Para los lineamientos principales de mi argumentación en este punto puede seguirse Maia Neto, J.

R.: The Christianization of Pyrrhonism, Kluwer Academic Publishers, Dordrecht, Boston, Londres, 1995, pp. 10ss.

24 M. T. Cicerón, Cuestiones Académicas, UNAM, México, 1980, p. 47.

25 Maia Neto, J. R.: op. cit., p. 11. 
bastantes puntos de contacto con la posición montaniana en los Essais, a saber, con una ética de la moderación y una posición de ecuanimidad con respecto a la diversidad del mundo basada en una moderada clase de asentimiento.

Pero, de un modo más general, es el motto sextiano, base de sus "normas" de la vida escéptica, esto es, su "seguir las apariencias" 26 , con un consecuente tratamiento de la realidad fenoménica bajo un modo no epistémico, el que puede leerse en filigrana en las letras de los Essais y esto, en definitiva, es lo que permite, en un primer momento, poner en cuestión el supuesto carácter diluido del escepticismo montaniano en pro de una opción moralmente dogmática.

Pero, ¿y qué decir del otro límite relacionado con éste de la moralidad, el del conocimiento de sí, que también se sostendría dogmáticamente? Podemos apuntar igualmente a las corrientes pirrónicas, ya que aunque el "descubrimiento del yo" no sea en éstas un tema tan presente como lo es en el autor renacentista, no es menos cierta la filiación que puede establecerse entre el "conocimiento" del yo, de corte escéptico, defendido por Michel de Montaigne en sus escritos y aquel que, de nuevo sin renunciar a su escepticismo exhiben quizá de un modo menos desarrollado los escritores de las corrientes escépticas antiguas.

Mais nostre condition porte que la cognoissance de ce que nous avons entre mains est aussi esloignée de nous, et aussi bien au dessus des nues, que celle des astres. ${ }^{27}$

En voylà assez pour verifier que l'homme n'est non plus instruit de la connoisance de soy en la partie corporelle qu'en la spirituelle. Nous l'avons proposé luy mesmes à soy, et sa raison à sa raison, pour voir ce qu'elle nous en diroit. Il me semble assez avoir montré combien peu elle s'entend en elle mesme.

Et qui ne s'entend en soy, en quoy se peut-il entendre?28

Parece pues posible aceptar, siquiera sea a título de hipótesis, la posibilidad de una presencia escéptica en los textos montanianos, pero ésta, ¿de que tipo es? ¿Puede adscribirse a una corriente concreta del escepticismo antiguo? O, más bien, ¿será una figura completamente nueva la que dibuja Montaigne en la impremeditada filosofía de los Essais? Y, no menos importante, ¿cuál es su peso en el conjunto

\footnotetext{
26 Sexto Empírico: Esbozos pirrónicos, Gredos, Madrid, 1993, I, 7, 13.

27 II, 12, 519: "Pero nuestra condición comporta que el conocimiento de aquello que tenemos entre manos esté tan alejado de nosotros, y muy por encima de las nubes, como el de los astros".

28 II, 12, 539: "Tenemos bastante para verificar que el hombre no está más instruido del conocimiento de sí mismo en la parte corporal que en la espiritual. Le hemos propuesto a sí, y a su razonamiento, su razón, para ver que nos diría. Me parece que he mostrado cuan poco entiende sobre ella misma. Y, quien no se entiende a sí mismo, ¿qué puede entender?”. La mejor defensa que conocemos de este punto, la existencia de una cierta subjetividad escéptica en la antigüedad, puede encontrarse en los polémicos textos de Fine, G.: "Sextus and External World Scepticism", en Oxford Studies in Ancient Philosophy, 24 (2003), pp. 341ss y Fine, G.: "Subjectivity, Ancient and Modern", en J. Miller (ed.): Hellenistic and Early Modern Philosophy, Cambridge U.P., Cambridge, 2003, pp. 192ss.
} 
del proyecto textual del autor francés, concretamente con su posicionamiento moral y el paralelo esbozo del yo que traza en su obra?

\section{Montaigne rupturista: entre irracionalismo e irresolución}

Para muchos autores, relevantes en el panorama de los estudios montanianos es un error leer, como empezamos haciendo nosotros, a Montaigne desde la Antigüedad. Hacer al autor francés heredero de una tradición o tradiciones como las expuestas en esbozo no permite ver lo que de rupturista hay en su escepticismo, aquello por lo que inaugura una forma "positiva" de la skepsis irreductible a la de los añejos modelos pirrónicos. ${ }^{29}$

Sin embargo, en muchos casos los autores que defienden tales argumentos están refiriéndose tan sólo a la versión que del pirronismo ha dado Sexto Empírico, teniendo poco cuidado de atender, como hemos hecho nosotros, a las anteriores variantes del mismo, proporcionando una visión monolítica de las corrientes pirrónicas que no se compadece con el carácter dúctil, polimorfo y mudable del pensar aporético.

Sea no obstante concedido para poder argumentar con esta opción interpretativa que el único modelo con el que cabe contrastar la supuesta presencia del escepticismo en los textos montanianos es el sextiano. Y así, de acuerdo con esta concesión cabe decir, siguiendo la argumentación de estos autores, que la esencia del escepticismo antiguo pasa por la triada de isosthenia, epoché y ataraxia. ${ }^{30}$ Junto con esto el pirronismo contendría un par de presupuestos que aligeran su supuesta radicalidad y ruptura con el resto de escuelas helenísticas, a saber: la existencia de una instancia comparativa, que permite la ponderación de las opiniones, y la idea de una representación estable del objeto de ponderación. Es decir, en suma, que si algo define al pirronismo será la defensa de una cierta estabilidad, tanto en su procedimiento como en su meta (la ya mencionada de la ataraxia).

Frente a ello, el perfil escéptico montaniano se caracterizaría por todo lo contrario y así, mediante la sustitución de la isosthenia por la asthenia (o yuxtaposición indefinida de representaciones borrosas y móviles), la suspensión de la epoché en

\footnotetext{
${ }^{29}$ F. Brahami: "Des Esquisses aux Essais, l'enjeu d'une rupture", en F. Moureau (ed.): Le scepticisme au XVI et au XVII siècle, A. Michel, Paris, 2001, p. 121. Éste es el autor más destacado en la defensa de la ruptura del escepticismo moderno con el antiguo, encarnado en la corriente de los escritos de Sexto Empírico. Aún cuando trataremos de cuestionar sus tesis más radicales al respecto de esta novedad montaniana, no podemos dejar de destacar el carácter renovador de sus estudios, a los que en buena medida se debe la consideración filosófica que sobre Montaigne ha venido dándose en estos últimos años.
}

30 Brahami: op. cit., p. 121. 
favor de la constante toma de posición y el borrado de la ataraxia como meta del escepticismo, se daría cuenta de la movilidad incesante de la condición humana.

De esta manera, la crítica de la presunción humana, de la vanidosa razón del hombre y de su enfermiza curiosidad

Les hommes mescognoissent la maladie naturelle de leur esprit: il ne faict que fureter et quester, et va sans cesse tournoiant, bastissant et s'empestrant en sa besongne, comme nos vers de soye, et s'y estouffe. "Mus in pice". Il pense remarquer de loing je ne sçay quelle apparence de clarté et verité imaginaire; mais, pendant qu'il y court, tant de difficultez luy traversent la voye, d'empeschemens et de nouvelles questes, qu'elles l'esgarent et l'enyvrent. 31

se resuelve en un escepticismo de nuevo cuño, con acentos distantes y distintos de los antiguos, pese a repetir los cuestionamientos sobre la capacidad de los sentidos

Ce propos m'a porté sur la consideration des sens, ausquels gist le plus grand fondement et preuve de nostre ignorance. Tout ce qui se connoist, il se connoist sans doubte par la faculté du cognoissant; car, puis que le jugement vient de l'operation de celuy qui juge, c'est raison que cette operation il la parface par ses moiens et volonté, non par la contrainte d'autruy, comme il adviendroit si nous connoissions les choses par la force et selon la loy de leur essence. Or toute cognoissance s'achemine en nous par les sens: ce sont nos maistres. 32

y, en suma, pese a la reutilización de los tropos pirrónicos a la hora de plantear problemas a las dos fuentes principales de conocimiento, razón y experiencia:

Il n'est desir plus naturel que le desir de connoisance. Nous essayons tous les moyens qui nous y peuvent mener. Quand la raison nous faut, nous y employons l'experience, Per varios usus artem experiencia fecit:

Exemplo mostrante viam,

Qui est un moyen plus foible et moins digne; mais la verité est chose si grande, que nous

31 III, 13, 1044-1045: "Los hombres desconocen la enfermedad natural de su mente: no hace sino husmear y rebuscar, dando sin cesar tumbos, forjando su obra y enredándose en ella, como los gusanos de seda, hasta que al fin se ahoga. "Mus in pice" ("Ratón en la pez", proverbio latino recogido por Erasmo en sus Adagios, II, III, 68 ). Cree columbrar a lo lejos cierta apariencia de claridad y verdad imaginaria, mas, mientras corre hacia ella, crúzanse en su camino tantas dificultades, tantos obstáculos y tantas nuevas búsquedas, que se pierde y se embriaga".

32 II, 12, 571-572: "Este objetivo me ha llevado a la consideración de los sentidos, en los cuales yace el fundamento y la prueba más grande de nuestra ignorancia. Todo lo que conocemos, lo conocemos sin duda por la facultad del que conoce, porque, en tanto que el juicio procede de la operación del que juzga, es razonable que esta operación la ejecute por sus medios y su voluntad, no por presión de nadie, como pasaría si conociésemos las cosas por fuerza y según la ley de su esencia. Y todo conocimiento se encamina hacia nosotros a través de los sentidos: ellos son nuestros maestros". 
ne devons desdaigner aucune entremise qui nous y conduise. La raison a tant de formes, que nous ne sçavons à laquelle nous prendre; l'experience n'en a pas moins. La consequence que nous voulons tirer de la ressemblance des evenements est mal seure, d'autant qu'ils sont tousjours dissemblables: il n'est aucune qualité si universelle en cette image des choses que la diversité et varieté. 33

Así pues, en Montaigne habrá una diferencia esencial con respecto al modelo de Sexto, en todos y cada uno de sus elementos principales. Desde el estilo acumulativo de la escritura montaniana, que provoca la mencionada asthenia, ya que las opiniones presentadas no serían ponderadas, sino que su relación sería la de una contigüidad indefinida, hasta el voluntarismo de suscitar tal situación anímica, ajena a la skepsis clásica donde la epoché resultaba de una imposibilidad de tomar decisión alguna.

Todos los elementos apuntan a esa diferencia de naturaleza entre el escepticismo de ambas épocas y, en el fondo, tal pluralidad en las modificaciones puede reunirse en una disparidad que, según esta interpretación, subyace como un todo a tales cambios. Y es que la isosthenia, desde esta lectura, implica una doble duración: de las representaciones y del espíritu en que estas se concretan, mientras que en Montaigne se empezó a dar una práctica de la experiencia del pensamiento en fluctuación (de sus contenidos y del alma que los contendría), que lleva a una recusación en toda regla del principio de ponderación en que se sostendría el edificio sextiano, la propia alma atravesada por el flujo de sus fantasías.

Montaigne habría transformado profundamente el escepticismo heredado de la antigüedad, no con el empleo de nuevos argumentos, sino mediante un cambio en el sentido de éstos. Si los antiguos buscaban llegar a una tranquilidad del espíritu o ataraxia, ahora tal objetivo es hostil a una condición humana constituida por una movilidad incesante ${ }^{34} \mathrm{y}$, además, un imposible, dado el desfallecimiento de isosthenia y epoché, ligados a ese desvanecimiento del espíritu en los flujos de la imaginación y emociones que constituyen al sujeto no sustancial moderno.

\footnotetext{
33 III, 13, 1041: "No hay deseo más natural que el deseo de conocimiento. Probamos todos los medios que pueden llevarnos a él. Cuando nos falla la razón, usamos de la experiencia "Per varios usus artem experiencia fecit:/ Exemplo mostrante viam" ("El arte nació de la experiencia e intentos repetidos, y el ejemplo enseño el camino" (Manilio, I, 59), que es un medio más débil y menos digno; mas es la verdad cosa tan grande que no debemos desdeñar ningún camino que a ella nos lleve. Tiene la razón tantas formas que no sabemos a cual agarrarnos, no tiene menos la experiencia. La consecuencia que queremos sacar de acontecimientos parecidos es insegura, pues son siempre distintos: no hay ninguna cualidad tan universal en esta imagen de las cosas como la diversidad y la variedad". Nótese que ya en la Apología es la razón fuertemente sometida a crítica y será precisamente De la experiencia, la encargada de consagrarse al dominio de la experiencia.

${ }^{4}$ Ch. Larmore en V. Carraud y J.-L. Marion (eds.): Montaigne: scepticisme, métaphysique, théologie, PUF, París, 2004, p. 15.
} 
En consecuencia como indica en su estudio clásico Cassirer, en este caso, e iniciando la versión moderna del escepticismo, con el objeto desaparece también el concepto de "sujeto" como norma unitaria y fija, deviniendo el individuo una sucesión de estados pugnantes entre sí35. En realidad, toda "verdad" postula una relación fija entre lo "interior" y lo "exterior", pero los dos elementos de la relación se mantendrían en Montaigne en constante cambio resultando finalmente en un borrado de la dicotomía subjetivo/objetivo.

$\mathrm{Y}$ es que, de un modo general, puede decirse que Montaigne no aspira a una filosofía como posición estable y definitiva, sino que, siempre fascinado por el movimiento incesante del espíritu, concibe de un modo auténticamente zetético el escepticismo, tal y como Sexto lo calificaba, esto es, como una "investigación sin término"36, pero como el autor antiguo nunca llegó a plantear seriamente, ya que su meta principal, la ataraxia, se oponía, desde estas lecturas, a ello. ${ }^{37}$

Montaigne, pues, siempre pondrá entre interrogantes la capacidad del ser humano de llegar a un conocimiento de la realidad del mundo o de los designios divinos, pero al contrario que Sexto (en esta lectura), los Essais si abundan en tomas de posición a lo largo de los diversos libros y ediciones, sin importar las abundantes contradicciones que ello implique. El núcleo de la estrategia montaniana es la conciencia de la precariedad, de la movilidad de las opiniones, característica del sujeto no sustancial esbozado en su pintura del yo con lo que, en definitiva, puede dar su asentimiento a ideas ambiciosas, pero siempre consciente de que otros, incluyéndose él mismo en otro momento, quizá no estén de acuerdo con la posición defendida.

Pero, volviendo al plano general de los partidarios de la innovación radical del escepticismo montaniano, cabe todavía preguntarse, a la vista de estos dos ejes de la metamorfosis del escepticismo moderno, la nueva concepción de la subjetividad y el movilismo zetético de las opiniones, cuál podría ser el motivo de tan grandes cambios por respecto a la skepsis antigua, y en esta cuestión central existe una divergencia importante en el seno de la propia lectura rupturista de los Essais.

35 Cassirer, E.: El problema del conocimiento en la filosofía y en la ciencia modernas, vol. I, FCE, México, 1953, p. 201.

36 Sexto Empírico: op. cit., 1, 3, 7.

37 Esta idea, defendida explícitamente por Larmore, Ch.: op. cit., p. 22, concuerda con el espíritu de la posición que estamos exponiendo, constituyendo su otro eje central, junto con el de la subjetividad no sustancialista, de la defensa de la radical ruptura del escepticismo montaniano, y por ende moderno, con el antiguo. Tanto una como otra serán puestas en cuestión a lo largo de estas páginas, mostrando como, en primer lugar, es posible encontrar indicios de una zetesis coherente y compatible con el objetivo de la ataraxia en el escepticismo sextiano (Olaso, E. de: "Zetesis", en Manuscrito, XI: 2 (1988), pp. 7ss) y, en segundo lugar, como tales elementos también están presentes en una cierta reflexividad escéptica (sin que con ello defendamos completamente tampoco, como veremos, el partido "tradicionalista", esto es, la vertiente interpretativa que defiende la continuidad del pensamiento escéptico antiguo en Montaigne, minimizando o eludiendo toda referencia a sus innovaciones). 
De esta manera, para algunos, como especialmente Brahami, Montaigne actualiza la potencia irracional de las creencias, revelando que el espíritu no es una sustancia cerrada sobre sí, capaz de autarquía y autonomía, sino que siempre está habitado por representaciones cuya fuerza afectiva es determinante 38 . Y tal modificación cercana al irracionalismo tiene un vínculo estrecho con la clave de lectura principal del susodicho autor, empleada para entender la radical ruptura del escepticismo montaniano con la tradición clásica, a saber: el papel de la divinidad católica en un panorama de pensamiento pagano.

El Dios del catolicismo monoteísta, desde esta lectura, cambia la base de las corrientes escépticas, en tanto que asentada en un racionalismo de fondo que no se compadece con la concepción relativa, contingente y arbitraria de la razón humana, a la luz de la omnipotencia divina. El escepticismo montaniano es aquí profundamente diferente del antiguo desde el momento en que, como fruto del contacto con la religión cristiana, la razón y su capacidad de poner en suspenso las opiniones confrontadas de las corrientes "filosóficas" paganas son puestas en crisis. En definitiva, ésta será la tesis sostenida de manera principal por esta versión del rupturismo, que la reapropiación cristiana de una corriente pagana como la del escepticismo alteró ésta profundamente. 39

De este modo, la razón, como facultad lógica de discernimiento, sólo puede sostenerse, desde esta lectura, sobre un asiento ontológico, el del alma como sustancia y así la crítica a la facultad racional del alma irá en este Montaigne del brazo de la puesta en cuestión de su fundamento sustancial supuesto. Y tal radicalidad crítica, a su vez, tendría su origen en una concepción de la divinidad propia de ciertas versiones del cristianismo, la ya mencionada del fideísmo, que entienden a éste como absolutamente trascendente por relación al mundo.

Tal análisis crítico de la razón, pues, si bien tiene una raíz sextiana, está interpretado a través de las categorías cristianas y entendido, en realidad, como un medio preparatorio, instrumental, para hacer espacio a la fe, como la mejor instrucción para la recepción de la palabra divina salvadora del espíritu (aunque el alma se habrá constituido, desde esta perspectiva, por una corriente de afectos sin representación, como un yo no inscrito en la intimidad del individuo, sin identidad asignable). ${ }^{40}$

Con ello volvemos a la constatación inicial en relación con esta interpretación no racionalista del Montaigne radicalmente innovador, que ahora puede enlazarse con la propuesta antropológica que deriva, desde esta lectura, de su escepticismo y

38 Brahami, F.: "Scepticisme", en Ph. Desan (ed.): Dictionnaire de Michel de Montaigne, Champion, Paris, 2004, p. 893.

39 Brahami, F.: Le scepticisme de Montaigne, PUF, Paris, 1997, p. 6.

40 Brahami, F.: op. cit., p. 90. No podemos dejar de estar de acuerdo con ciertos aspectos de esta lectura escéptica de la subjetividad brindada por Brahami, donde casi podría decirse que la vanidad o presunción, constante blanco de las críticas de Montaigne en los Essais, se constituye en una cuasi-categoría ontológica y donde el conocerse es un experimentar la propia inanidad. 
que lo diferencia de otros avatares clásicos del pirronismo y es que, para el autor francés, como se sigue de lo antedicho, la razón será reducible a imaginación y la sensación pasará a ser una función vital del organismo viviente humano antes que un mero instrumento de la ciencia. Reconociendo la utilidad vital de la razón, que ira ligada al rechazo de su capacidad de decir la verdad, se desplaza así el centro de discusión en torno a las representaciones que entre académicos-pirrónicos, epicúreos y escépticos se había mantenido durante toda la época clásica del pensamiento occidental.

Esta crítica de la experiencia, pues, no se queda en mera repetición del escepticismo antiguo, antes bien, lo que aquí se da es la sustitución del debate epistemológico sobre la adecuación de la percepción al ser en favor de una investigación sobre la potencia de la percepción en el campo de los afectos. El autor francés verá en los sentidos unos testigos de toda fiabilidad a la hora de interrogarse sobre la vida, inmanentes en su imbricación orgánica y, sin embargo, completamente inútiles en cuanto las cuestiones a las que se apelase fuesen del orden trascendente de la verdad.

La única verdad objetiva que Montaigne reconoce será la que dispensa la Iglesia católica, los únicos principios a los que el hombre está sujeto, los revelados. Pero esto en realidad supone un separar la fe inspirada por Dios de las creencias que conforman nuestra vida espiritual ordinaria. Y si a esto le añadimos que la razón depotenciada por las críticas montanianas ha perdido sus características de universalidad y necesidad, el factor elemental del ser humano es ahora la creencia desnuda. ${ }^{41}$

Frente a esta lectura rupturista del escepticismo en los Essais, favorable a la tradicional interpretación de un Montaigne fideísta, pero opuesta a la filiación de su skepsis con las corrientes racionalistas griegas clásicas, podemos encontrar otra posición defensora también de una innovación radical en el escepticismo moderno, encabezado por Michel de Montaigne, pero, al contrario que ésta, defensor de su cercanía a posiciones racionalistas y, en relación con ello, desafecta a toda interpretación fideísta del autor francés, siendo Giocanti su defensora más destacada.

Para esta exegeta el escepticismo montaniano representa también una práctica diversa de la skepsis griega, como se explicitaría ya desde las propias opciones estilísticas del autor francés, cuyo texto más escéptico no es, ni se reduce a, la Apología, sino que impregna sus diversos ensayos, entendiéndose más su escritura en términos de un ensayar un pensamiento irresuelto que como expresión explicita de un tratado de filosofía escéptica a la sextiana con sus formulaciones aporéticas y sus tropos bien estructurados. 42

\footnotetext{
41 Brahami, F.: Le travail du scepticisme. Montaigne, Bayle, Hume, PUF, Paris, 2001, pp. 59ss.

42 Giocanti, S.: Penser l'irrésolution. Montaigne, Pascal, La Mothe le Vayer, Champion, París, 2001, p. 11. Ya que de otro modo, no se expresa correctamente el carácter autocancelante del escepticismo montaniano, comprometido con una respuesta a las objeciones clásicas al escepticismo ya mencionadas, como especialmente en este caso la del carácter autocontradictorio de la formulación escéptica.
} 
Además, el escepticismo radical montaniano, frente a las lecturas del escepticismo postcartesiano, desde esta interpretación, a la vez que se enfrentó críticamente con la filosofía y la ciencia establecidas, sin miras a su reconstrucción sobre nuevas bases dogmáticas, se encaminó a la elaboración de una ética que no atendiera a verdades reveladas y sentimientos religiosos trascendentes, rechazando cualquier afinidad electiva con el mencionado fideísmo, contra la lectura rupturista de los partidarios de la interpretación no racionalista. ${ }^{43}$

Más aún, y nuevamente en oposición a la interpretación de Brahami, para esta lectura lo propio del escepticismo moderno es una práctica discursiva y ética que usa la razón escépticamente, contentándose con permanecer en una duda insuperable que hace oscilar a la fe. Y en este sentido, también la antropología escéptica esbozada por Michel de Montaigne en sus Essais adquiere una coloración diferente, no siendo la fantasía y la creencia desnuda sus núcleos esenciales, sino una irresolución de la razón que lleva a creer en las representaciones que se imponen en el fuero interno sin firmeza, dada la ausencia de estabilidad que las caracteriza, y donde la incertidumbre es el elemento central objetiva y subjetivamente.

El escepticismo montaniano sera entendido desde aquí como una práctica de la razón que preside una ética especifica, nacida de la renuncia a cualquier afirmación de omnipotencia de la misma racionalidad sobre pensamiento y acción, con el objetivo final de pensar tal ethos como hecho a nuestra medida, sin trascendentalismo alguno (siquiera sea uno por vía de la gracia).

Pero, al mismo tiempo, tal escepticismo moderno radical, representado por Michel de Montaigne, no se reduce a las corrientes pirrónicas, sino que la desconfianza en la regularidad de la experiencia que, según esta lectura, caracteriza al escepticismo sextiano, y el rechazo de la supuesta indiferencia, insensibilidad y afasia característica del de Pirrón, ${ }^{44}$ llevan, de nuevo, a plantear la novedosa ruptura que la skepsis de los Essais supone. El escepticismo de Montaigne es desde esta perspectiva, discursivo y racional, no conduciendo a la puesta en cuestión de la filosofía en pro de una ascesis escéptica, pero tampoco de un cierto empirismo ajeno a la radicalidad de la irresolución montaniana.

El escéptico, frente al dogmático, se rinde a la inconstancia de la razón, buscando sacar provecho intelectual a su flexibilidad, pero arruinando con ello la estabilidad del logos y la presunta constancia del ser. Con ello se da una nueva concepción de la racionalidad, donde el logos liga el pensamiento y está sostenido por el discurso pero, frente a la tradición racionalista de la corriente escéptica clásica, este logos no se tiene en nada dada su volubilidad y labilidad. Dos son así los usos de la razón, suspensivo o escéptico, por un lado, y afirmativo o dogmático, por el otro.

43 Giocanti, S.: op. cit., p. 30.

44 Walton, C.: "Montaigne on the Art of Judgement", en J. E. Force y R. A. Watson (eds.): The Sceptical Mode in Modern Philosophy, Martinus Nijhoff, Dordrecht, Boston, Lancaster, 1988, p. 94. 
Frente a la lectura irracionalista, el juicio está aquí concernido con el balanceo incesante de la deliberación y la dificultad del conocer reside en la exigencia de estabilidad del mismo, aparentemente incompatible con la realidad del movimiento incesante a la que en su irresolución se encuentra sometido. ${ }^{45}$ El juicio en Montaigne, siguiendo la terminología kantiana, no es determinante sino reflexivo. Y así, el autor francés obtiene sus normas de los particulares, los estudia como aquello que permite un orden y su funcionamiento, liberado de la ilusión de universalidad. ${ }^{46} \mathrm{El}$ juicio será siempre local y contingente y ser escéptico no implicará, frente a las lecturas clásicas o la del rupturismo no racionalista, renunciar a él o suspenderlo, sino, más bien, admitir su concurrencia con una multiplicidad de perspectivas diferentes a la suya, exponiéndose a la refutación y al cambio siempre posibles, de las propias posiciones y opiniones asumidas.

En definitiva, podemos decir que más allá de las diferencias esenciales que separan a ambas versiones de la concepción rupturista del escepticismo de los Essais para con la corriente clásica del pirronismo, reducido en muchos casos a la versión dada por Sexto Empírico del mismo, serán los dos elementos clave señalados al inicio de nuestra disquisición los que articulan su respuesta a los defensores del carácter tradicional, continuista y de mera transmisión del escepticismo clásico por Michel de Montaigne, a saber: el de la movilidad zetética de las opiniones y el de la nueva concepción de la subjetividad (dispersa o irresuelta) presente en los Essais.

El escepticismo, entendido como "práctica de la investigación", como ejercicio sin término cuyo principal efecto es el de probar permanentemente la insuficiencia e incertidumbre de "nuestras" adquisiciones provisionales, se opone, desde esta lectura, a la concepción clásica del pirronismo (sextiano), hasta rechazar incluso, radicalmente, frente a éste, la experiencia como Ersatz de la ciencia. ${ }^{47} \mathrm{Y}$, en su defecto, frente al género del tratado en el que todavía se encuadró el texto sextiano, Montaigne inventa el ensayo. Éste manifestaría la contingencia e incertidumbre fundamental de las aserciones, reconociendo en ellas el reflejo del sujeto que las enuncia en un momento dado y no el de la imagen del objeto sobre el que tratan. Es la suya una forma radical de enunciación que pone entre paréntesis la validez del discurso doctrinal sin, frente al escepticismo clásico, impedir su proferencia. 48

\footnotetext{
45 Mathias, P.: Montaigne ou l'usage du monde, Vrin, París, 2006, p. 84.

46 Baillon, E.: "Une critique du jugement", en Revue Internationale de Philosophie, 46: 181-2 (1992), p. 144. De ahí la abundancia de pasajes donde Montaigne se abandona a las enumeraciones extensas y dispares, oponiéndose con ello a cualquier visión totalizadora, buscando, antes bien, maximizar las posibilidades y reducir las presunciones, dando carta de naturaleza a los sentidos particulares por encima de los generales.

47 Este será el sentido del último de los ensayos de Michel de Montaigne, que rechaza el principio de semejanza sobre el que se asientan, por ejemplo, las aseveraciones por inducción.

48 Tournon, A.: "Suspense philosophique et ironie: la zététique de l'essai", en Montaigne Studies, 12: 1-2 (2000), p. 47.
} 
La formula de la zetética en Montaigne no se lleva a cabo mediante el uso de enunciados dubitativos ocasionales, sino mediante un retorno del pensamiento sobre sí que deja desamparado al lector ávido de enseñanzas. Los Essais abundan en máximas, observaciones incisivas, discusiones, testimonios y convicciones pero todo ello enunciado a título de "ensayo", considerado a distancia, sin garantía de adquisición definitiva, alejándose así de cualquier objetivo relacionado con la ataraxia sextiana o, por qué no, de la afasia pirrónica.

Y, a su vez, como hemos dicho, volviendo sobre los dos ejes de la interpretación rupturista, tal concepción de la novedad ensayística montaniana deja traslucir, por un lado, el deseo de despojar de cualquier ilusión de certidumbre a una búsqueda sin término radicalmente zetética y, al mismo tiempo, evidencia el carácter elusivo del sujeto que las pronuncia, volviéndose tal zetesis reflexivamente sobre el propio yo y siendo la persecución de un yo siempre en fuga la que viene a ocupar el primer plano de la indagación filosófica.

\section{Montaigne tradicionalista: entre pirrónicos y académicos}

Algunos autores, con Popkin y destacados discípulos suyos, como Jose Maia Neto, a la cabeza, han destacado, sin embargo, frente a esto aquellos aspectos que permiten hablar, más bien, de una decidida continuidad entre el pensamiento clásico escéptico y su difusor renacentista, Michel de Montaigne (así como el de algunos de los sucesores de éste), oponiéndose, directa o indirectamente a las tesis de los defensores del rupturismo entre escepticismo antiguo y moderno en la figura del escritor francés.

Destacando el anclaje de los juicios en torno a la filosofía del autor de los Essais en la tradición clásica ${ }^{49}$, no necesariamente, sin embargo, han sido estos autores los defensores de un escepticismo ajeno a las innovaciones propias del contacto con el cristianismo y con aquellas corrientes del pensamiento vigentes todavía en el Renacimiento francés, incluyéndose en esta tolerancia de las metamorfosis de la skepsis la famosa tesis del fideísmo montaniano. 50

49 Stevens, L. C.: “The meaning of 'Philosophie' in the Essais of Montaigne”, en Studies in Philosophy, LXII (1965), p. 153.

50 Aunque, en algunos casos, tal tolerancia o aceptación de las modificaciones sea más matizada, siendo la continuidad con la corriente pirrónica, o con una mixtura de pirronismo, al modo como lo entendiera Sexto Empírico y el academicismo, lo que destaque y quedando cuestiones como la del fideísmo en un segundo plano (será este el caso de otro destacado defensor de la continuidad que representaría en las tradiciones escépticas Michel de Montaigne, Gianni Paganini, quien en la interpretación de Cavaille, J.-P.: "Le retour des sceptiques", en Revue philosophique de la France et de l'Etranger, 2 (1998), p. 203, opta por un discreto acuerdo formal, permitido y limitado por el trabajo de distanciación propia del pirronismo, entre fideísmo y escepticismo montaniano, muy lejos de una concepción ortodoxa y militante de un catolicismo contra-reformista, como la que puede desprenderse de ciertas lecturas del fideísmo del autor francés). 
De esta manera, frente a críticas de corte rupturista, como la realizada por Ian Maclean 51 , que ven un deslizarse de una cierta regla de vida y de un criterio de juicio en los textos del autor francés que se enfrentaría de manera radical a la epoché sextiana, cabe apelar aquí al ya mencionado dictum del seguir las apariencias, a la propuesta de abandonarse y dejarse llevar por los fenómenos y las subsiguientes normas vitales que Sexto redactara en su Hipotiposis. 52

Y contra la inversión del escepticismo antiguo que habría operado Montaigne, en la interpretación, por ejemplo, de Brahami, mediante el desafío a las capacidades humanas presente en la idea cristiana del Dios omnipotente, con una concepción de la antropología montaniana de corte no racionalista, así como una cierta "teología" centrada en la gracia y en el carácter sobrenatural de la fe, se propone ahora un Montaigne mucho más sobrio y distante de cualquier lectura teológica comprometida.

Y así, si bien, en este sentido, ciertos defensores de una conexión más estrecha entre las corrientes escépticas clásicas y la moderna, en su versión montaniana, admiten el contacto y conocimiento por parte del autor francés de, al menos, la teología negativa, que insistió en la omnipotencia divina y el correlativo carácter limitado del saber humano, rechazan éstos cualquier salida mística, como la existente en estas corrientes, así como alguna otra cosa que no fuese un claro decalage entre tales especulaciones medievales y la orientación más humanista de Montaigne, mayormente marcada por las huellas estoica y pagana en general que por la de una verdadera piedad cristiana. 53

Es más, y ya centrando la crítica en aquellos aspectos centrales comunes a todas las versiones de la lectura rupturista del escepticismo de Montaigne, cabe decir que ni la "pintura del yo", la supuestamente novedosa subjetividad sin sujeto propuesta por Montaigne en sus Essais, ni la zetesis, como búsqueda sin término radical, escapan a la alegación de precedentes clásicos en la lectura de los autores que propugnan la continuidad de tradiciones.

Y así, la mencionada proyección de una crítica a la visión sustancialista de la subjetividad puede en realidad entenderse como un despliegue de algo que in nuce ya esta presente en las corrientes del mundo antiguo, la reflexividad escéptica, la inflexión subjetiva de la skepsis. De esta manera, la originalidad de Montaigne residirá en un retomar el escepticismo antiguo bajo la forma de una "filosofía de la subjetividad", en un explicitar lo que ya está presente en el escepticismo antiguo, con una concepción epistemológica del "sujeto" naturalizada, no absoluta sino al lado de las demás criaturas, con recursos cognitivos particulares y limitados. ${ }^{54}$

51 Cavaille, J.-P.: op. cit., p. 204.

52 Sexto Empírico: op. cit., I, 11, 23-24.

53 Paganini, G.: Le redécouverte du phénomène, manuscrito, 2007.

54 Eva, L.: A figura do filósofo. Ceticismo e subjetividade em Montaigne, Loyola, Sao Paulo, 2007, p. 488 . 
Lo mismo cabe decir de la zetesis escéptica, al modo en que la han caracterizado los defensores de una clara ruptura entre ambos períodos temporales en que el escepticismo resurgió con fuerza. Y es que si en Montaigne se trata de que la filosofía corresponda a un ensayo o ejercicio del juicio, puede defenderse que tal concepción está heredando aquellos textos en que Sexto Empírico, o Diógenes Laercio, polemizan con la idea de la filosofía escéptica como doctrina o hairesis, ${ }^{55}$ esto es, con aquellas lecturas del pirronismo sextiano en que éstos se entienden a sí no como adhiriéndose a una doctrina o secta concreta, sino, antes bien, como engarzándose con un género filosófico caracterizado por la práctica argumentativa, destinada a la discusión de las más variadas tesis y consciente de sus límites a la hora de establecer tales tesis como verdades.

Es más, tal actividad argumentativa escéptica en Montaigne se fusionaría con la mencionada tarea de autoexamen o conocimiento de sí, llegando a reconocer así que el estatuto del juicio es intrínsecamente finito y limitado, pero a su vez destacando el carácter central del mismo juicio en la práctica escéptica, y nada de ello, desde la perspectiva de los defensores de la continuidad de las tradiciones, se opone a la comprensión central de la zetesis o quaestio escéptica clásica, disociable de la ataraxia a la que se mantendría en el horizonte, como meta más o menos clara. ${ }^{56}$

De hecho, el punto crítico común a las dos vertientes principales de la lectura rupturista, la ausencia de ataraxia o de afasia como limite al que reconduce una también cuestionada epoché, palidecería, a juicio de estos autores, ante tales similitudes entre las corrientes de las diferentes épocas. Y más aún, si atendiéramos a como Montaigne había reintroducido el concepto de fenómeno o "fantasía", tomándolo a partir de la lectura sextiana del problema de la aparalaxia, o imposibilidad de distinguir con certidumbre entre apariencias verdaderas y falsas ${ }^{57}$ (y con la modificación tal introducción supondría en un contexto dominado por la tradición medieval de las species), parece paradójico no considerar a Montaigne como un pirrónico, sextiano, tan sólo porque no diese cuenta ortodoxamente de la suspensión del juicio como un estado de tranquilidad del alma que reconduce a la ataraxia.

Pero incluso en el seno de una lectura continuista del escepticismo de los Essais como ésta es posible encontrar fisuras y cabe señalar como un punto de disputa, precisamente, el carácter netamente pirrónico, o mejor dicho sextiano (ya que tanto rupturistas como continuistas comparten una visión un tanto reducida históricamente del pirronismo, teniendo apenas en cuenta las variaciones que esta corriente puede haber sufrido en el curso del tiempo), de los textos del filósofo de Burdeos.

$Y$ es que algunos han señalado el conocimiento montaniano de la tripartición de la filosofía realizado por Sexto Empírico

55 Sexto Empírico, Diógenes Laercio: Esbozos pirrónicos. Vida de Pirrón, Círculo de Lectores, Barcelona, 1996, I, 20.

56 Eva, L.: op. cit., p. 232.

57 Paganini, G.: op. cit. 
Quiconque cherche quelque chose, il en vient à ce point: ou qu'il dict qu'il l'a trouvée, ou qu'elle ne se peut trouver, ou qu'il est encore en queste. Toute la philosophie est départie en ces trois genres. Son dessein est de chercher la verité, la science et la certitude. Les Peripateticiens, Epicuriens, Stoïciens et autres ont pensé l'avoir trouvée. Ceux-cy ont estably les sciences que nous avons, et les ont traittées comme notices certaines. Clitomachus, Carneades et les Academiciens ont desesperé de leur queste, et jugé que la verité ne se pouvoit concevoir par nos moyens. La fin de ceux-cy, c'est la foiblesse et humaine ignorance; ce party a eu la plus grande suyte et les sectateurs les plus nobles. 58

y de este modo, destacando la concepción de la skepsis como interrogación siempre abierta a la investigación, parece indicarse que la verdadera zetética montaniana escapa al dogmatismo negativo achacado por el propio Sexto a la Academia escéptica, con su denegación de la posibilidad de conocer la verdad. Más aún, no sólo responde Montaigne con su "Que sçai-je?" a la aporía de las formulas catalépticas académicas, que en tanto que autoreferenciales incurren en autorrefutación, sino que las propias cuestiones académicas, los criterios de verosimilitud y probabilidad, manejados por Arcesilao o Carneades, caerían también bajo la égida de una intencionalidad antiacadémica resucitada por el autor francés bajo una clara inspiración sextiana. 59

Y, sin embargo, por otro lado, si bien es cierto que Montaigne ceba sus críticas contra el escepticismo académico como representantes de un dogmatismo negativo, no lo es menos que en sus propios Essais nunca cita al autor de las Hipotiposis, ni lo reconoce como fuente y sí hace uso prolongado y abundante de pasajes ciceronianos sobre el escepticismo académico, empleándolos paradójicamente incluso en aquellos momentos en que trata de la excelencia y utilidad de la posición pirrónica:

Nous sçavons les choses en songe, dict Platon, et les ignorons en verité.

"Omnes pene veteres nihil cognosci, nihil percipi, nihil sciri posse dixerunt; angustos sensus, imbecillos animos, brevia curricula vitae"

Cicero mesme, qui devoit au sçavoir tout son vaillant, Valerius dict que sur sa viellesse il commença à desestimer les lettres. Et pendant qu'il les traictoit, c'estoit sans obliga-

58 II, 12, 482: "Cualquiera que busca alguna cosa llega a este punto: o dice que la ha encontrado, o que no puede encontrarse, o que aún está buscándola. Toda la filosofía está dividida en estos tres géneros. Su objetivo es buscar la verdad, la ciencia y la certeza. Los peripatéticos, los epicúreos, los estoicos y otros han creído encontrarla. Estos han establecido las ciencias que tenemos y las han tratado como cosas ciertas. Clitómaco, Carneades y los Académicos han desesperado de su búsqueda y han juzgado que la verdad no se puede concebir con nuestros medios. El fin de estos es la debilidad y la ignorancia humanas; éste es el partido que ha tenido más numerosos seguidores y los miembros más nobles".

59 Paganini, G.: Scepsi Moderna. Interpretazioni dello scetticismo da Charron a Hume, Busento, Cosenza 1991, p. 17. 
tion d'aucun parti, suivant ce qui luy sembloit probable, tantost en l'une secte, tantost en l'autre; se tenant tousjours sous la dubitation de l'Academie,

"Dicendum est, sed ita ut nihil affirmem, quaeram omnia, dubitans plerumque et mihi diffidens". 60

Es por ello posible hablar, más bien, de una valoración positiva, a la vez que crítica, de ambas corrientes escépticas de la Antigüedad, evidenciándose más aquello que comparten ambas frente al dogmatismo que lo que escolarmente puede separarlas, a saber, su integridad intelectual, entendiendo por tal la integridad del intelecto, la capacidad de ejercer plenamente su principal facultad, la del juicio, sin encontrarse limitado por creencias apriorísticas como en el caso de los dogmáticos.

Et où les autres sont portez, ou par la coustume de leur païs, ou par l'institution des parens, ou par rencontre, comme par une tempeste, sans jugement et sans chois, voire le plus souvent avant l'aage de discretion, à telle ou telle opinion, à la secte ou Stoïque ou Epicurienne, à laquelle ils se treuvent hippothequez, asserviz et collez comme à une prise qu'ils ne peuvent desmordre. "Ad quamcunque disciplinam velut tempestate delati, ad eam tanquam ad saxum adhaerescunt", pourquoy à ceux cy ne sera il pareillement concedé de maintenir leur liberté, et comsiderer les choses sans obligation et servitude?61

Pero si esto fuese así, entonces, ¿cómo defender coherentemente una continuidad entre la posición de Sexto Empírico y aquella que representa Michel de Montaigne? Ciertamente si ya desde el principio de los Essais el autor francés se caracterizó por realizar una amalgama entre textos pirrónicos y académicos, no era debido, como se ha señalado, a su desconocimiento de las antiguas distinciones realizadas por Sexto Empírico en sus Hipotiposis sino, más bien, al intento de construir una visión personal del escepticismo en la que no cabrían los esquemas y mol-

\footnotetext{
60 II, 12, 481: "Sabemos las cosas en sueños, dice Platón, y las ignoramos en realidad. 'Casi todos los antiguos dijeron que nada podía conocerse ni percibirse, ni saberse; que teníamos los sentidos limitados, los espíritus débiles y la vida breve' (Cicerón: Cuestiones Académicas, I, XII, 44). Cicerón mismo, que debía al saber todo su valor, dice Valerio que cuando llegó a la vejez comenzó a estimar menos las letras. Y mientras las trató, lo hizo sin ligarse a ningún partido, siguiendo aquello que le parecía probable, a veces de acuerdo con una secta, otras con otra, manteniéndose siempre bajo la duda de la Academia. 'Es preciso que hable, pero de manera que no afirme nada, todo lo cuestiono, dudo casi siempre y desconfió de mi mismo' (Cicerón: De divinatione, II, 8, 8)".

61 II, 12, 483-484: "Y mientras que los otros son llevados, o por la costumbre de su país o por la educación de sus padres, o por el azar, como por una tormenta, sin juicio ni elección, incluso a menudo antes de la edad del discernimiento, a aquella o ésta opinión, a la secta estoica o a la epicúrea, con lo cual se encuentran hipotecados, sujetos y enganchados como a un anzuelo del que no pueden soltarse: 'Se adhieren a cualquier disciplina, tanto como una tempestad a una roca' (Cicerón: Cuestiones Académicas, II, III, 8), ¿porqué a estos no se les concederá de manera similar mantener su libertad y considerar las cosas sin obligación ni servidumbre?".
} 
des escolares a los que, por desgracia, las vertientes enfrentadas de la interpretación o exégesis sobre el escepticismo montaniano nos tienen acostumbrados.

\section{Conclusión: Montaigne, ni ruptura radical ni continuidad tradicional}

Es en este sentido que tanto la lectura continuista como la rupturista pueden requerir una revisión amplia que diese cuenta de la "naturaleza" del escepticismo montaniano en sus propios términos y no aquella que desde una óptica más atenta a las semejanzas y diferencias de tal skepsis con sus "modelos" tradicionales han venido realizando sus críticos en las diferentes corrientes interpretativas. Una lectura más cuidadosa de nuestro autor debe dar cuenta de la renovadora interpretación operada en el interior de las corrientes pirrónicas por parte del pensador francés por ejemplo en cuestiones tan centrales como las de las objeciones al escepticismo señaladas en el primer punto de nuestro artículo.

Y así, en el caso de la autorrefutación del escepticismo, los actuales defensores de lo que Brennan llamaría "un escepticismo rabioso" 62 , extienden la privación o suspensión de toda creencia escéptica hasta el extremo universal, tratando de hacer la posición escéptica implausible (e invivible). De este modo, proponen éstos luego una solución en forma de admisión de ciertas creencias, aunque con una actitud menos comprometida hacia ellas. 63

Sin embargo, la respuesta montaniana a un posible diálogo con los críticos del escepticismo clásico no tiene por qué admitir esta respuesta. Antes bien, retomando la contestación sextiana a estas objeciones les daría Montaigne una respuesta propia que incluye entre sus características la de formularse en un modo interrogativo y tener, por esta vía, una vinculación directa con una noción de subjetividad e intersubjetividad escéptica de nuevo cuño.

\section{[A] "Nil sciri quisquis putat, id quoque nescit}

An sciri possit quo se nil scire fatetur"

L'ignorance qui se sçait, qui se juge et qui se condamne, ce n'est pas une entiere ignorance: pour l'estre, il faut qu'elle s'ignore soy-mesme. De façon que la profession des Pyrrhoniens est de branler, douter et enquerir, ne s'asseurer de rien, de rien ne se respondre. 64

62 Brennan: 2000: 63.

63 Frede: 1997, 2007a: 2ss.

64 II, 12, 482: " 'Si alguien cree que no se puede saber nada, aún si puede saber no sabe, ya que confiesa no saber nada' (Lucrecio: De rerum natura, vol. II, IV, 469s, modificado en la versión montaniana para convertir un ataque contra los escépticos en un argumento en su defensa). La ignorancia que se sabe, que se juzga y que se condena, no es una ignorancia completa; para serlo tiene que ignorarse a sí misma. De modo que la profesión del pirrónico es moverse, dudar e investigar, no asegurarse de nada, no responder de nada". 
$\mathrm{Y}$ es que, por un lado, siguiendo las estrategias sextianas cabe decir que el escepticismo montaniano tiene respuesta a la acusación de la imposibilidad de vivir una vida escéptica y su correlativa atribución de un carácter autorrefutatorio dando cuenta del carácter dialéctico de sus argumentos, que tomados de los dogmáticos, sin ser asumidos como propios, dan pie a la refutación de estos haciendo uso de sus mismas argumentaciones. ${ }^{65}$ Por ello no es necesario la admisión de un grupo de creencias mínimas e incluso puede en última instancia, como hiciera Sexto, admitir tal objeción sin considerarla un inconveniente para el escepticismo al modo en que podían entenderlo las corrientes pirrónicas, dado el carácter terapéutico de las mismas. ${ }^{66}$ Es en este sentido, y de acuerdo con las estrategias argüidas por Sexto en sus Hipotiposis, que plantearía Montaigne la posibilidad de vivir una vida con sentido, más o menos coherente como posición filosófica.

Por otro lado, la respuesta montaniana se plantea además de manera práctica, enunciándola desde un sujeto determinado, teniendo en cuenta el carácter reflexivo del escepticismo y tomando en serio aquello que para Burnyeat sería una objeción notable para la skepsis, esto es, la distancia que el yo toma respecto de sí mismo al vivir una vida plenamente escéptica. ${ }^{67}$

Y en definitiva, a esta remozada, a la vez que heredada de la tradición, noción de sujeto y a la correlativa comprensión pragmática, intersubjetiva, del escepticismo, deberíamos prestar atención en lo sucesivo para poder captar la especificidad de la skepsis montaniana, oscilante entre la Escila de la repetición de las tradiciones y la Caribdis de la diferencia moderna, ni rupturista radical ni continuista tradicional, fuera de los estrechos esquemas y categorías de comprensión a que los diferentes enfoques actuales la someten y con relevancia propia en sus términos en su momento y también para el pensamiento actual.

\section{Vicente Raga Rosaleny}

Corporación universitaria empresarial Alexander von

Humboldt, sede Armenia-Quindío (Colombia),

Departamento de Psicología y Unidad de investigaciones

vraga@cue.edu.co

65 McPherran: 1987: 298.

66 McPherran: 1987: 301ss, Laursen: 1992: 87ss. Se entiende aquí la terapia escéptica al modo de un tratamiento homeopático, que trata la enfermedad con dosis de la misma para ponerle remedio y, a la manera de un purgante, que eliminara del cuerpo a la vez enfermedad y el bebedizo que produce la cura: "Acerca de todas las expresiones escépticas, debemos saber primero que no aseguramos en absoluto que sean verdaderas, ya que podemos decir en verdad que pueden ser también refutadas por ellas mismas, puesto que están incluidas en las cosas a las que se aplican, de la misma manera que los fármacos catárticos no sólo expulsan del cuerpo los humores, sino que también ellos mismos se expelen con los humores" (Sexto, 1993: I, 28, 206).

67 Burnyeat: 1983: 147s. 